\title{
Perspective \\ Effective Strategies for Project-Based Learning of Practical Electronics
}

\author{
Faisal Mohd-Yasin (D) \\ School of Engineering and Built Environment, Griffith University, Nathan, QLD 4111, Australia; \\ f.mohd-yasin@griffith.edu.au
}

check for updates

Citation: Mohd-Yasin, F. Effective Strategies for Project-Based Learning of Practical Electronics. Electronics 2021, 10, 2245. https://doi.org/ 10.3390/electronics10182245

Academic Editors:

Adrián Segura-Robles, María

Elena Parra-González, Jesús

López Belmonte, Antonio

José Moreno Guerrero and

Tony Givargis

Received: 26 July 2021

Accepted: 10 September 2021

Published: 13 September 2021

Publisher's Note: MDPI stays neutral with regard to jurisdictional claims in published maps and institutional affiliations.

Copyright: (C) 2021 by the author. Licensee MDPI, Basel, Switzerland. This article is an open access article distributed under the terms and conditions of the Creative Commons Attribution (CC BY) license (https:// creativecommons.org/licenses/by/ $4.0 /)$.

\begin{abstract}
Some universities offer specific project-based learning (PBL) courses in the third year of their electronic engineering degree to equip undergraduate students before they embark on industrial attachment and/or a capstone project. This course exposes those students to full design cycles at circuit and system levels. Students also pick up practical skills, such as component selection, circuit troubleshooting, printed circuit board design, and market analysis. This perspective offers the author's reflections on effective learning and teaching strategies for this purpose, after running such a course for the past 10 years at Griffith University. In earlier years, students' have complained about lack of direction and overloading, which are common issues being reported in PBL courses. In response, we have implemented scaffolding and balanced evaluation criteria for assessment, providing formative feedback, and we have designed integrated assessment items. As a result, average marks for the cohort and the percentage of students that receive the grade of high distinction have increased in the past five years. These strategies might be of help at other learning institutions that offer similar courses.
\end{abstract}

Keywords: project-based learning; electronic engineering; circuit; sensor; printed circuit board

\section{Introduction}

It is universally acknowledged that the crown jewel of the undergraduate electronic engineering degree is the senior capstone project. This course offers the senior students the opportunity to embark on an independent research project, be it industry- or researchbased. Due to its importance, there have been many studies on this subject [1-4]. Before embarking on this path, however, the students must be equipped with skills such as project management, project proposal, breadboard prototyping, troubleshooting of faulty circuits, printed circuit board design, demonstration and presentation, writing technical report, etc. This is especially important when the senior students are doing their projects in industries. The general assumption is that the core courses from the first three years of the program, such as basic electronics [5-7] and analog circuit [8-12], could furnish some of these skills through their laboratory-based assignments. In many cases, however, the scope is too narrow and the duration of design assignment of those courses is too short to make an impact. Moreover, many students do not have wide range of knowledge and experience to propose and undertake an independent project that is proportionate to their capabilities.

Hence, some institutions provide specific project-based learning (PBL) course to address these deficiencies. Each one has different style of implementations $[13,14]$. At Griffith University, this course is called "Practical Electronics", and the author has been in charge of it since 2011. In the early years, students were frustrated with unclear expectation for the design project and often felt overloaded and stressed. It should be noted such problems have been well-reported in many PBL courses $[15,16]$. In response to these complaints, there have been many evolutions in the course structure and delivery, which eventually resulted in improved learning outcomes and students' satisfaction. The objective of this perspective is to share four strategies that have been implemented in Practical Electronics 
course, namely scaffolding, balanced evaluation criteria for assessment, providing formative feedback, and designing integrated assessment items. As a result of these strategies, students' learning outcomes improves in the last five cohorts. The average marks for $2016,2017,2018,2019$, and 2021 cohorts are $64.75 \%, 63.73 \%, 62.76 \%, 72.95 \%$, and $70.86 \%$, respectively. In addition, the percentage of students who received the top grade of high distinction for the same cohorts are $0 \%, 13.3 \%, 10.7 \%, 12.5 \%$, and $29.6 \%$. The data for 2020 are not used, because the author was on sabbatical and was not teaching that cohort. Moreover, the laboratory-based activities for that year were shifted to simulation-based projects due to the campus lockdown during the pandemic.

While the targeted audience for this perspective is the practitioners of PBL in electronic engineering, we believe that these strategies could be applied to other related disciplines, as well. Hence, most of the analog electronics details are placed in appendices to make this perspective concise and easy to follow by the non-experts. The electronic engineers are encouraged to read through the appendices in details, as these documents contain many useful information on analog circuits. The rest of the paper is organized as follow. In the second section, we briefly describe the course structure, learning activities, and assessment items. The third section is the "meat" of this perspective. It details the effective strategies to increase students' satisfaction and learning outcomes. The last section concludes this perspective with some additional thoughts. Figure 1 summarizes the course structure and learning strategies.

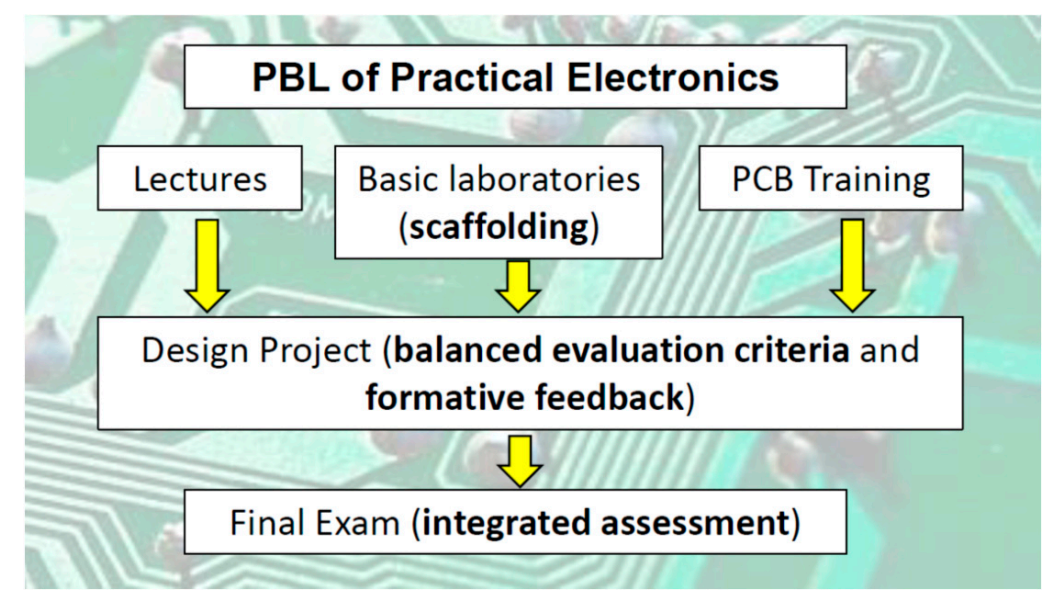

Figure 1. Course structure for Practical Electronics is provided. Additionally, the implementation of four effective strategies (in bolded text) is also shown.

\section{Course Structure, Learning Activities, and Assessment Items}

The main learning outcome is to equip students with practical skills in developing an electronic product at circuit and system levels. The course has weekly lectures and laboratory sessions for a total of 12 weeks. The contents and the schedule of learning activities are shown in Appendix A. A well-known book for practicing engineers entitled Arts of Electronics is used [17]. While a majority of circuit-based contents are taken from this book, as listed in the second column of Appendix A, the last three topics, namely design and fabrication of printed circuit board (PCB), sensors and actuators [18,19], and system design and market analysis [20], are prepared by the course lecturer. As shown in the third column of Appendix A, the weekly laboratory sessions are divided into three phases. The first stage is used to train students with Altium Designer [21] to make them proficient in PCB design. The breadboard prototyping of operational amplifier-based circuits is delivered in the second stage. After that, the third stage provides avenue for the students to work on their independent design projects. They have to prepare prototypes on the breadboard and/or PCBs for demonstration on week 11. For the latter, the PCB layouts must be submitted on week 9 , and the boards get fabricated by the in-house workshop 
the following week. Upon the return of the PCBs on week 10, students then prepare for component assembly and testing for the final demonstration on week 11.

Appendix B shows the list of assessment items, due dates, and marks. All of them are geared towards achieving the central learning outcome of this course. The first assignment is the project proposal, worth $5 \%$. The details are provided in Appendix C. The main purpose is to provide formative feedback to students on the viability of their proposed projects. The marks and detailed feedback are given to each group via email before the commencement of the actual project. The second assignment is called introductory lab. The main objective is to familiarize students with basic circuit design, circuit troubleshooting, and proficiency with equipment. The laboratory manuals are provided in Appendix D. Students have to design and demonstrate five basic modules on the breadboard, namely non-inverting amplifier, summing amplifier, active band-pass filter, integrator, and voltage regulators. These modules are chosen as they constitute the basic building blocks of most electronic circuits. Each module is worth only one mark to build students' confidence with their hands-on capabilities. The third assignment is the design project, worth $50 \%$. The details are written in Appendix E. This is the major assessment item of the course, as students need to go through the full design cycles, from the preliminary breadboard prototyping to the final presentation on the PCB. In addition, they also have to write a technical report to document their projects. Due to the workload and limited test benches, students are encouraged to work in a group of two, although some prefer to work alone. In order to differentiate the contributions from the group works for the final grade of this course, the fourth assessment item is the final exam, which is worth $40 \%$. This controlled, individual-based assessment is two hours in duration and contains subjective questions to test students' overall understanding of the lecture materials, laboratories, and, most importantly, their own design projects.

\section{Effective Strategies}

This section discusses the effective learning and teaching strategies to improve the learning outcomes and student satisfaction for this course. Before going into these, two pertinent points needs to be made beforehand. First, a prerequisite for any successful course is the lecturer's full proficiencies on the subject matters. In the context of this course, such lecturer must master the wide arrays of electronic circuit designs, as well as PCB design and fabrication. Second, the lecturer in charge must have intimate and direct knowledge of all students and their projects, instead of depending on the feedback from the lab demonstrator/graduate teaching assistant. Both factors are crucial for the success of the four strategies as elaborated next.

\subsection{Scaffolding}

Scaffolding is a well-known strategy in PBL [22]. In the context of this course, it was implemented by using three approaches to ensure the successful completion of the design project. In the first approach, the design of the second assignment, i.e., the introductory lab, ensures students that they already have the basic modules that could be combined together to create a complex circuit on the bread board. Furthermore, the introductory lab trains students with the circuit troubleshooting procedures and familiarity of the equipment. As a result, students are more confident of working with a much complex circuit in the design project.

The second approach involves the use of exemplar specifications to provide clear expectation on the scope and complexity of the design project. Such help from the course lecturer has been known to facilitate effective learning in PBL [23]. In this course, three project titles and specifications have been provided, and their details are given in Appendix F. The projects are proportional-integral-derivative controller, function generator, and temperature sensor. All of them meet the minimum requirement of the circuit complexity; these are mature circuits and well-tested, and they can be constructed with components that are readily available in the laboratories. The second project, i.e., the function generator, 
has proven to be popular with students, as they could reuse the amplifier and integrator modules from the second assignment. It should also be noted that students are not mandated to choose one of specifications in Appendix F as their projects. It is common for the excellent students to instead propose their own projects, after getting approval from the course lecturer.

The third approach involves the use of past-year reports that are made available to the current students. These reports are sourced from the best students in past cohorts with their written permissions. Students like this approach because they could see the whole design life cycle for their upcoming projects from past reports of similar specifications. However, the use of this strategy is not without a risk. Several students may see these past-year reports as a shortcut route to complete their projects [24]. Thus, they attempt to copy the final schematic from these reports and passed it on as their own, without going through the hassles of complete design life cycle. Based on our experiences with the analog electronic project, however, this shortcut rarely works because there are many hidden factors that enable successful circuit implementation. Even with a fool-proofed schematic that is sourced from a past-year exemplar, an electronic cookbook, or the hobbyist website, one has to consider other factors, such as the quality of the bread board, components, and equipment for the circuit to work correctly.

\subsection{Balanced Evaluation Criteria}

For PBL courses and capstone projects, well-designed evaluation processes are needed to fairly assess the performance of students that are working on different projects [25]. In the context of this course, we have come up with five criteria, namely design and testing thought processes, circuit complexity, level of understanding, quality of the outputs, and quality of the report. Each has a maximum mark of 10. Appendix $G$ shows the marking rubric that clearly differentiate the achievements of these criteria at different marking bands. These evaluation criteria are presented and clarified before the commencement of the design project, so students have clear expectation and can strategize on their intended implementation. In specific, the first and second criteria are design to provide a balanced assessment to cover projects of differing complexities and rigors. Two extreme examples are explained herein. On the one hand, one project could have been a fairly complex circuit that takes time to be completed, and hence lack of rigorous testing. On the other hand, another project could be a fairly simple circuit, but makes it up by having elaborated characterizations. Such balanced criteria are crucial to cater for students with different approaches on their projects. The other three assessment criteria are straightforward. The "level of understanding" criterion encourages students to start with basic circuit that they fully understand, and progress for there. This is commonly known as developmental learning [26]. The fourth criterion, i.e., "quality of output", is split into two categories. The first is on the demonstration of the circuits, either on bread board or PCB. The second is on the quality of PCB. Such a split is proposed to ease the stress level of the students, as not all of them would be able to demonstrate their project on working PCBs. Finally, the last criterion, i.e., "quality of report", is to train students to write a concise report. Chapter 2 of the report forces them to perform market analysis of the cognate commercial products. The past-year exemplars prove to be a great help in guiding the students to satisfy this requirement.

\subsection{Formative Feedback}

A formative feedback for improved learning contains four elements, namely specific, actionable, timely, and respectful [27]. We incorporate these elements in written and oral feedback for all assessment items in this course [28]. The design project is a time-sensitive assignment. Hence, for one particular project, the course lecturer should only pick only one of two main weaknesses related to the circuit design or testing, and ignoring the rest until the major problems are resolved. Such a technique reduces students' stress levels and encourages them to learn at their own pace. The first assignment, i.e., the project proposal, 
is the first avenue to provide formative feedback. Three key items to be looked at are the circuit complexity, the availability of the components in the laboratory, and students' understanding of testing mechanisms by way of their proposed application. After the communication of written feedback via email, some students are requested to discuss their proposals with the course lecturer in person during the laboratory sessions. The purpose is to weed out any choice of wrong projects, as some students inadvertently took the circuits from the hobbyist website of electronic cookbooks without proper understanding. In order to increase students' confidence and motivation, the marking of the project proposal is performed leniently, as shown in the last part of Appendix C.

The informal and in situ oral feedback are provided during the second assignment, i.e., the introductory lab. The main purpose of such feedback is to train the students in regard to hands-on skills, such as circuit design, circuit troubleshooting, and achieving proficiency with the operation of equipment, such as dual power supplies, multimeter, and oscilloscope. In some cases, the course lecturer and lab demonstrator also need to train students on the management of time and stress, especially when the circuits are not working. This is also the avenue for the teaching team to identify students that require extra helps and those that are having slower learning curves. This informal feedback continues on when the third assignment commences, i.e., the design project. In general, most students will have less reliance in term of seeking assistances from the course lecturer/lab demonstrator as their project progress further. This is a good sign, as they are incrementally developing their design and testing thought processes.

The summative feedback in written form is provided after the completion of the design project. In order to provide effective feedback, the course lecturer needs to be involved in the monitoring of all projects from the proposal stage to the assessment of submitted report. All students will be provided with detailed comments to explain the awarded marks for each marking criterion (see Appendix G). The main purpose is to let the students know of their strengths and weaknesses while undergoing the full design cycle of electronic product. The expectation is for them to improve their practical skills before they are going for industrial attachment and/or performing the senior capstone project. Unfortunately, due to the privacy concern, the sampled feedback to students could not be shown in this perspective.

\subsection{Integrated Assessment Items}

This course contains four assessment items (see Appendix B). All of them are designed to be aligned to the main learning outcome of this course. This alignment could easily be understood for the first three assignments, namely project proposal, introductory $\mathrm{lab}$, and design project. Since all three items involve group work, in order to provide the differentiator and linkage to the main learning outcome, the fourth and individual assignment, i.e., the final exam, has also been designed to test students' understanding and reflection on their completed design project. The sampled exam questions are provided in Appendix H. It contains subjective questions that covers the lecture materials, as well as open-ended questions about the design projects. The examples of the latter are in Questions 1(a), 1(b), 2(a), 2(c), 2(e), 3(b), 3(d), 4(b), 4(d), and 4(3) of that appendix. The answers to these questions are unique and project specific, and hence demands the course lecturer to have intimate knowledge of individual projects.

It should be noted that most PBL courses in analogue electronic do not have this direct linkage between final exam to the design project. The former and latter are normally separately prepared to test the theoretical and practical contributions, respectively. A recent article did report a correlation in terms of a student's performance between both [29]. In order to create an effective evaluation, we strongly believe that the open-ended exam questions (such as in Appendix H) are crucial in the future of all PBL courses. It will encourage the students to understand and reflect their knowledge on the design project instead of memorizing contents from the lecture materials for the final exam. Admittedly, the preparation of such questions takes time and efforts on the lecturer's side. 


\section{Conclusions}

The implementation of PBL for the course "Practical Electronics" was documented in this perspective. It is an important course to equip electronic engineering students with industrial settings. In earlier years, students complained about the lack of direction and overloading, which are common issues being reported in PBL courses. Four learning and teaching strategies have been gradually employed since 2016, as described in Section 3. As a result, students' learning outcomes have been improving. The average marks for each cohort are 64.75\% (2016), 63.73\% (2017), 62.76\% (2018), 72.95\% (2019), and 70.86\% (2021). Similarly, the percentage of students who received the top grade of high distinction is on the rise: $0 \%$ (2016), $13.3 \%$ (2017), $10.7 \%$ (2018), $12.5 \%$ (2019), and $29.6 \%$ (2021).

We would like to take this opportunity to emphasize two points for successful PBL course in practical electronics. First, the proficiencies of the course lecturer as the subject matter expert and his/her direct involvement in the laboratory assignments are critical to ensure successful implementation of the four strategies. Second, it is utterly important to understand the students' motivation for undertaking such a course. In the author's own experiences, most of them are not aiming for high grades, but instead want to learn about the practical skills that they know would be useful after graduation. Hence, a continuous and formative feedback, as well as consideration of the students' different learning rates, must be given to prepare them for the professional life.

Looking ahead, the course could benefit from future improvements. One aspect that needs to be looked at is the PCB timeline. Many students complained of the lack of time to work on the PCB design of their projects, as they were given only a few weeks, due to the tight deadline. Moreover, the training of Altium Design was conducted at the beginning of the semester, so some of the lessons were forgotten by week 8 . There are two possible solutions to this problem. First, the PCB components could be omitted due to time constraint, but this will not address the industry's need. Second, the current coverage could be split into two semesters for the breadboard prototyping and PCB implementation, respectively. However, this proposal will require the omission of another important subject that are necessary for electronic engineering program.

Funding: This research received no external funding.

Institutional Review Board Statement: Not applicable.

Informed Consent Statement: Not applicable.

Data Availability Statement: Data is contained within the article.

Acknowledgments: The author is indebted to staff and students for their feedback in improving the design and delivery of Practical Electronics course at Griffith University.

Conflicts of Interest: The author declares no conflict of interest.

Appendix A

\begin{tabular}{ccc}
\hline Week & Lecture Topics & Lab Activities \\
\hline 1 & Foundations & Altium training \\
2 & Operational amplifier & Altium training \\
3 & Passive and active filters & Altium training \\
4 & Timers and oscillators & Introductory lab \\
5 & Voltage regulation and power conversion & Introductory lab \\
6 & No lecture (Easter holiday) & Introductory lab \\
7 & BJT and FET & Design project \\
8 & PCB design and fabrication & Design project \\
9 & Sensors and actuators & Design project \\
10 & System design and market analysis & Design project \\
11 & No lecture & Final demonstration \\
12 & Summary & No lab. \\
\hline
\end{tabular}


Appendix B

\begin{tabular}{ccc}
\hline Assessment Tasks & Due Date & Marks \\
\hline Project proposal & Week 4 & $5 \%$ \\
Introductory lab & Weeks 4 to 6 & $5 \%$ \\
Design project & Weeks 7 to 11 & $50 \%$ \\
Final exam & Exam week & $40 \%$ \\
\hline
\end{tabular}

\section{Appendix C}

Name: Proposal

Type: Assignment-Planning Document

Weight: $5 \%$

Task description:

Students in a group of two will submit a brief proposal for their design project. The document should contain PPT slides to address the following items:

- $\quad$ Project title and specifications.

- Block diagram that shows inputs, outputs, displays, signal conditioning circuits, etc.

- Proposed circuits to implement the functions in the block diagram.

- Proposed application(s), which must be accompanied by proposed testing methods.

The emphasis will be on the use of analogue circuitries to process the input signal(s). Therefore, the use of digital logic circuitries and/or programmable devices will not be accepted.

\section{Choice of project:}

The suitable projects could be chosen from the following options:

1. Past-year projects. Three exemplars are provided.

2. Own idea or websites. Please discuss with the course lecturer if you choose this option.

\section{Schedule:}

Weeks 1 to 3: Students form their groups and discuss on the selection of the suitable projects.

Week 4: The slides in PDF must be submitted online. Only one submission per group is required.

Week 6: Course lecturer to e-mail specific feedback to each group with the marks.

\section{Marking criteria:}

>4.5 marks: Present clear specification and block diagram/circuits/applications with reasonable amount of analogue complexities in their projects.

4 to 4.5 marks: Understand the circuits, but lack of analogue complexities and is required to add functions to the proposed project, and/or need to define the application(s) and testing method(s).

$<4$ marks: Need to increase the understanding of the proposed circuits, and/or need to add analogue circuits to increase the complexities, and/or need to define the application(s) and testing method(s).

\section{Appendix D}

Name: Introductory Lab

Type: Assignment-Laboratory

Weight: $5 \%$ 
The main objective of this assignment is to familiarize you with the circuits that could be used in your design project assignment. You are required to complete all five parts within the allocated time. After the completion of each, please demonstrate the result to the teaching team. They will progressively record your marks in the database. You do not have to write a lab report for this assignment.

As mentioned during the lectures, operational amplifier (op-amp) is a very versatile integrated circuit (IC). Hence, the first four parts of this assignment cover the common applications of this IC. We will use LM358 for part 1 and 2, and TL074CN for part 3 and 4. You are advised to locate the data sheet for both op-amps. Please review these sheets carefully and make note of the key information such as pin identification, minimum and maximum power supplies, bandwidth, etc.

\title{
Part 1-Operational Amplifier (op-amp) as a non-inverting voltage amplifier (1 mark)
}

Construct a non-inverting amplifier circuit with a voltage gain of 10 . Use the supply voltages of $\pm 12 \mathrm{~V}$ to power the LM358 and the sinusoidal input of $100 \mathrm{mVpp}$ to feed the input of the op-amp. Please observe and verify the correct output on the oscilloscope.

\section{Part 2-Op-amp as a difference amplifier (1 mark)}

Construct a difference amplifier circuit with a voltage gain of 10 . Use the supply voltages of $\pm 12 \mathrm{~V}$ to power the LM358, and the sinusoidal input voltages of 200 and 100 $\mathrm{mVpp}$ to feed both inputs of the op-amp. Please observe and verify the correct output on the oscilloscope.

\section{Part 3-Op-amp as an active filter (1 mark)}

Pick one of the circuit configurations from the lecture notes to construct a band pass filter with a gain of 10, and the low and high cutoff frequencies of 1 and $5 \mathrm{kHz}$, respectively. Use the supply voltages of $\pm 12 \mathrm{~V}$ to power the TL074 and the sinusoidal input of $100 \mathrm{mVpp}$ to feed the input of the op-amp. You need to devise a strategy to be able to demonstrate the working functionalities of your filter.

\section{Part 4-Op-amp as an integrator (1 mark)}

Refer to Figure 10 in the application note AN 31. Use the supply voltages of $\pm 12 \mathrm{~V}$ to power TL074 and the pulse input of $100 \mathrm{mVpp}$ with $50 \%$ duty cycle to feed the input of the op-amp. Set the switch to open. Construct the circuit by setting $\mathrm{f}=10 \mathrm{kHz}$. You need to devise a strategy to be able to demonstrate the working functionalities of your integrator.

\section{Part 5-Voltage regulators (1 mark)}

Voltage regulators are used to regulate and stabilize the DC voltage that comes from the power supplies. The main application is to provide a specific DC voltage levels for integrated circuits (ICs), such as op-amps.

1. Locate the data sheets for the LM7812 and LM7912 linear voltage regulators. Review these sheets carefully and observe specifications for the devices such as pin identification, minimum input voltage and maximum ratings.

2. By referring to the recommended circuits that could be found in their data sheets or other sources, use these voltage regulators to construct $\pm 12 \mathrm{~V}$ regulated supplies. Demonstrate these circuits using the input voltages from the lab's DC power supply.

\author{
Appendix E \\ Name: Design Project \\ Type: Assignment-Practice-Based Assignment \\ Total Weight: $50 \%$ \\ Task description:
}


Students will work in groups of two to complete a circuit design project from start to finish, moving through the following phases:

- Definition of project concept that is started during the proposal;

- Electronic circuit design that is started during the proposal;

- Bread board prototyping of the proposed circuit;

- Design of PCB for the proposed circuit;

- Assembly of the circuit on the PCB, once it is fabricated;

- Testing methodology that is geared towards the targeted application;

- Demonstration of the circuit meeting the design specifications;

- Documentation of the project in a formal written report.

\section{Components:}

This assignment has been designed so that you can make use of the components that are readily available in the laboratory. It is your choice to purchase other components at electronics stores at your own expense.

\section{Schedule:}

Week 6: After receiving the written feedback that was given by the lecturer for the proposal, make sure that you have all components.

Weeks 7 to 10: First, you will construct and test your proposed circuits on the breadboard. Then, you should design the PCB and submit it fabrication. Please be reminded that the PCB will be made in batches. Therefore, there is a turnaround time to get your PCB back from the workshop. Once the PCB is fabricated, you must assemble and solder the components on it, and perform the final testing.

Week 11: You must demonstrate the output of your project in front of the teaching team during the scheduled laboratory session. Then, the written report must be submitted on Friday of week 11. Please submit one report per group. The guidelines for writing this document are provided in the next section. Please be aware that the teaching team uses Turnitin to detect plagiarism.

Weeks 12-15: The teaching team will read all reports and then assign appropriate marks to each group according to the marking rubric. The marking breakdown and specific comments will be emailed to all groups.

\section{Guidelines for writing the report:}

1. The report must include the following chapters: (1) Introduction; (2) Market analysis; (3) Design methodologies; (4) Testing methodologies and results; (5) Analysis; and (6) Conclusion, as well as references and appendices.

2. Chapter 1 describes the project, its objectives and outcomes. It must also include a statement clearly outlining the activities completed by each group member.

3. Chapter 2 is the "system design" aspect of the report. You must describe the intended application(s) of your circuits, and tabulate similar products in the market. An online search will be required to accomplish this task. After studying your competitors' strength and weakness, you make arguments to sell your own product. The following factors can be used: retail price, offered functionalities, technical risks, compliance and standards, ease of installation and maintenances, ergonomics, environmental, social and ethical impacts, etc.

4. Chapter 3 emphasizes the design thought process (design methodology). You start with the overall block diagram of the project, and discuss the design and circuits of individual modules in details. You should also discuss the design considerations for PCB layout in this chapter.

5. Chapter 4 emphasizes on the testing thought process. Key results should be presented in figures, and they must be labeled properly. The high-volume data should be summarized in a table. A high-resolution photograph of the final product, with clear labels of the individual models should be provided.

6. Chapter 5 is your primary avenue to reflect on the knowledge that you have acquired from doing this independent project. You should list down the design evolutions and 
troubleshooting efforts to achieve what you propose in the specification, despite all the technical and non-technical challenges.

7. Chapter 6 summarizes the report, and provides suggestions for improvements (future works).

8. Please use IEEE format for the referencing and citation. The copy of IEEE citation guidelines is attached.

\section{Appendix $\mathrm{F}$}

\section{Exemplars for Design Project Assignment}

Three exemplars are provided. They have been chosen due to these factors: (1) meeting the minimum requirement of the analogue circuit complexity, (2) mature circuits and well-tested, and (3) the components to construct these circuits are readily available in the lab. All the exemplars make use of op-amp circuits to process the signals. Some are implemented in the introductory lab, while the rest could be found from the lecture slides and application notes.

\section{Example 1: Proportional-Integral-Derivative (PID) controller}

This is a versatile control system that is being used in many industrial applications. Circuit wise, it consists of a summer, amplifier, integrator and differentiator modules. In order to find the specific values for the components, you need to define the specific application. For example, suppose that you would like to control the temperature of a heater. Therefore, you need to precisely define the range of the output temperature that you want to feed back to the controller to change the input conditions. You must also choose the circuit that could be demonstrated on the oscilloscope. That is, the response time of the PID controller needs to be in several seconds to suite the response of the human's eyes.

\section{Example 2: Function generator}

This circuit produces sine, triangular and pulse waves with adjustable amplitude and frequency. The first stage is an astable multivibrator circuit that produces a square wave. The second stage is an integrator that produces the triangular wave, and the third stage is another integrator to produce the sine wave. You also need to add an amplifier to adjust the amplitude of the output signal. Similar to Example 1, the demonstration for the three waveforms on the oscilloscope need to be planned carefully.

\section{Example 3: Precision temperature sensor}

You are mandated to use 1N4148 silicon diode (available in the lab) as a temperature sensor and to display the DC output voltage in the range of 0 to $5 \mathrm{~V}$ to represent the temperature range of 0 to $100{ }^{\circ} \mathrm{C}$. The diode's sensing range is very small, about $+/-15$ $\mathrm{mV}$ for the temperature of 0 to $100{ }^{\circ} \mathrm{C}$ with an offset of $0.6 \mathrm{~V}$. Furthermore, that diode has a negative temperature coefficient, meaning that, as the temperature rises, the output voltage decreases. You need to use a series of the op-amp circuits to process the input signal from the diode in order to obtain the required output range.

\section{Appendix G}

\begin{tabular}{ccccc}
\hline Criteria/Mark & $\mathbf{9}$ to $\mathbf{1 0}$ & $\mathbf{7}$ to $\mathbf{8}$ & $\mathbf{5}$ to $\mathbf{6}$ & $<$ \\
\hline $\begin{array}{c}\text { Design and testing } \\
\text { thought processes }\end{array}$ & $\begin{array}{c}\text { Employ creative } \\
\text { circuits and testing } \\
\text { methods with superior } \\
\text { thought process. }\end{array}$ & $\begin{array}{c}\text { Employ common } \\
\text { circuits and testing } \\
\text { methods with clear } \\
\text { thought process. }\end{array}$ & $\begin{array}{c}\text { Employ common } \\
\text { circuits and testing } \\
\text { method with limited } \\
\text { thought process. }\end{array}$ & $\begin{array}{c}\text { No apparent efforts in } \\
\text { thought process to } \\
\text { achieve specific } \\
\text { specifications. }\end{array}$ \\
\hline
\end{tabular}




\begin{tabular}{|c|c|c|c|c|}
\hline Criteria/Mark & 9 to 10 & 7 to 8 & 5 to 6 & $<5$ \\
\hline $\begin{array}{l}\text { Complexity of the } \\
\text { project }\end{array}$ & $\begin{array}{l}\text { The project consists of } \\
\text { very complex analogue } \\
\text { circuits that } \\
\text { demonstrate significant } \\
\text { efforts by the designer. }\end{array}$ & $\begin{array}{l}\text { The project consists of } \\
\text { fairly complex } \\
\text { analogue circuits that } \\
\text { demonstrate more than } \\
\text { average efforts by the } \\
\text { designer. }\end{array}$ & $\begin{array}{c}\text { The project consists of } \\
\text { basic analogue circuits } \\
\text { that demonstrate } \\
\text { limited efforts by the } \\
\text { designer. }\end{array}$ & $\begin{array}{l}\text { The project does not } \\
\text { meet the minimum } \\
\text { specifications, and } \\
\text { demonstrates lack of } \\
\text { efforts by the designer. }\end{array}$ \\
\hline $\begin{array}{l}\text { Demonstrated level of } \\
\text { understanding }\end{array}$ & $\begin{array}{l}\text { Excellent, i.e., complete } \\
\text { understanding of all } \\
\text { aspects of the circuits. }\end{array}$ & $\begin{array}{l}\text { Good, i.e., reasonable } \\
\text { understanding of all } \\
\text { aspects the circuits. }\end{array}$ & $\begin{array}{l}\text { Basic understanding of } \\
\text { all aspects of the } \\
\text { circuits. }\end{array}$ & $\begin{array}{l}\text { Limited/confused } \\
\text { understanding of the } \\
\text { circuits. }\end{array}$ \\
\hline Quality of the outputs & $\begin{array}{l}\text { Excellent quality PCB, } \\
\text { with demonstration of } \\
\text { all functionalities. }\end{array}$ & $\begin{array}{l}\text { Good quality PCB with } \\
\text { demonstration of most } \\
\text { of the functionalities. }\end{array}$ & $\begin{array}{l}\text { Fair quality PCB with } \\
\text { basic demonstration of } \\
\text { the functionalities. }\end{array}$ & $\begin{array}{l}\text { Bad quality PCB with } \\
\text { no demonstration of } \\
\text { the functionalities. }\end{array}$ \\
\hline Quality of the report & $\begin{array}{l}\text { The report includes } \\
\text { succinct contents with } \\
\text { excellent analysis } \\
\text { chapter to enable the } \\
\text { teaching team to assess } \\
\text { the overall quality of } \\
\text { the project. }\end{array}$ & $\begin{array}{l}\text { The report includes all } \\
\text { the required contents, } \\
\text { and the information are } \\
\text { provided with } \\
\text { sufficient clarity to } \\
\text { enable the teaching } \\
\text { team to assess the } \\
\text { overall quality of the } \\
\text { project. }\end{array}$ & $\begin{array}{l}\text { The report includes all } \\
\text { the required contents, } \\
\text { but does not contain } \\
\text { sufficient clarity to } \\
\text { enable the teaching } \\
\text { team to assess the } \\
\text { overall quality of the } \\
\text { project. }\end{array}$ & $\begin{array}{l}\text { The report misses many } \\
\text { required contents to } \\
\text { enable the teaching } \\
\text { team to assess the } \\
\text { overall quality of the } \\
\text { project. }\end{array}$ \\
\hline
\end{tabular}

\section{Appendix $\mathrm{H}$}

\section{Final Exam Questions}

Question 1:

[10 marks]

(a) Using your own project as a reference, state one specific advantage and specific one disadvantage of creating printed circuit board (PCB) for the circuitries. [2 marks]

(b) Using your own project as a reference, describe one specific problem that you had encountered during the PCB design. Please also explain your solution to that problem. [2 marks]

(c) The PCB for Practical Electronics project is fabricated in-house. Supposed that it has been sent to professional PCB maker instead. Describe two specific improvements that could be made to the fabricated PCB. [2 marks]

(d) For the wet etching method, the PCB is dipped into chemical baths two times in a row. Provide the name of both chemicals and their purposes. [2 marks]

(e) State one advantage and one disadvantage of rapid PCB prototyping using computercontrolled machine. [2 marks]

Question 2:

[10 marks]

(a) Based on your own experience during the introductory laboratory or design project, describe one specific problem that you encounter when using capacitor in your circuit. Then, provide your explanation for the possible cause(s) of that problem. [2 marks]

(b) Describe the operation of an inductor as an energy storage device. Then, explain the reason for the infamous "voltage spike" that is caused by the inductor. [2 marks]

(c) Based on your own experience during the introductory laboratory or design project, describe one specific example on how the inaccurate measurement or low quality equipment had/could have affected the troubleshooting of the circuit. [2 marks]

(d) Suppose that your circuit operates with the bandwidth of $1 \mathrm{MHz}$ and the voltage gain of 100. Describe the most important parameter for selecting the operational amplifier. [2 marks]

(e) Using your own project as a reference, describe one specific problem that you encountered while employing operational amplifier. Please sketch the problematic circuit, and explain your solution to the problem. [2 marks] 
Question 3:

[10 marks]

(a) A frequency response graph must be plotted to examine the performance of a filter. In the absence of spectrum analyzer, propose two methods to come up with this graph using an oscilloscope. [2 marks]

(b) Suppose that you are tasked to develop a band pass filter circuit. It has the center frequency and bandwidth of $50 \mathrm{kHz}$ and $20 \mathrm{kHz}$, respectively. Unfortunately, it does not work when you build and test that whole circuit in the laboratory. Using a divide and conquer strategy, list the logical steps that you should have undertaken to troubleshoot the problems. Please be specific in your answers. [3 marks]

(c) A comparator relaxation oscillator, 555 timer, or crystal oscillator can be used to produce a pulse signal. Provide one unique advantage of each implementation. [3 marks]

(d) Suppose that you need to create an adjustable reference voltage ranging from 2 to $8 \mathrm{~V}$, with a fix voltage supply of $12 \mathrm{~V}$. Please suggest two different circuit configurations to achieve this. [2 marks]

\section{Question 4:}

[10 marks]

(a) State the reason/need for the evolution of power amplifier from Class A to Class B, and then from Class B to Class AB. [2 marks]

(b) Suppose that you are experiencing a "loading effect" in your circuit that has multiple stages. Please suggest two different circuits to fix the problem, using operational amplifier and a transistor, respectively. [2 marks]

(c) A microphone is composed of a thin film that acts as the acoustic sensor and a backplate. With aid of diagram, describe how the sound is converted to electrical signal using capacitive and piezoelectric mechanisms, respectively. [2 marks]

(d) Using your own project as a reference, identify the "weakest link" in your circuit, and provide justification for this selection. Then, suggest one specific solution that you could have taken to increase the reliability of your overall system. [2 marks]

(e) Suppose that your product has been chosen to be placed in a location that cannot be reached by service personnel and without access to electrical outlet. Can you suggest two possible advancements to the existing system to make sure that it is operable in those conditions? [2 marks]

\section{References}

1. Dutson, A.J.; Todd, R.H.; Magleby, S.P.; Sorensen, C.D. A Review of Literature on Teaching Engineering Design through Project-Oriented Capstone Courses. J. Eng. Educ. 1997, 86, 17-28. [CrossRef]

2. Mertz, R. A capstone design course [electrical engineering]. IEEE Trans. Educ. 1997, 40, 41-45. [CrossRef]

3. Born, R. A capstone design experience for electrical engineers. IEEE Trans. Educ. 1992, 35, 240-242. [CrossRef]

4. Pasya, I.; Al Junid, S.A.M.; Buniyamin, N.; Al-Junid, S.A.M. Overview of Capstone Project implementation in the Faculty of Electrical Engineering, Universiti Teknologi MARA, Malaysia. In Proceedings of the 2015 IEEE 7th International Conference on Engineering Education (ICEED), Kanazawa, Japan, 17-18 November 2015; pp. 95-99. [CrossRef]

5. Mohamed, M.; Jubadi, W.M.; Zaki, S.W. An implementation of POPBL for analog electronics (BEL10203) course at the Faculty of Electrical and Electronic Engineering, UTHM. J. Tech. Educ. Train. 2011, 3, 45-53. Available online: https://penerbit.uthm.edu. my/ojs/index.php/JTET/article/view/413/0 (accessed on 9 September 2021).

6. $\quad$ Etchepareborda, P.; Bierzychudek, M.E.; Carducci, L.; Veiras, F.E.; Zacchigna, F.G.; Corbellini, E.; Marra, S.G.; Iglesias, M.; Teggia, M.M.; Alvarez-Hamelin, J.I.; et al. A Project-Based Learning Method Applied to an Introductory Course in Electronics Engineering. In Proceedings of the 2018 IEEE World Engineering Education Conference (EDUNINE), Buenos Aires, Argentina, 11-14 March 2018; pp. 1-4. [CrossRef]

7. Chen, J.; Gao, F.; Kong, L.; Cui, L. Study on teaching methods of fundamental electrical courses in engineering education. In Proceedings of the 2018 5th International Conference on Industrial Engineering and Applications (ICIEA), Singapore, 26-28 April 2018; pp. 515-519.

8. Savant, B.N.; Pawar, S.S. Implementation of Project Oriented Problem Based Learning in the Analog Electronics Course. In Proceedings of the 2017 International Conference on Transforming Engineering Education (ICTEE), Pune, India, 13-16 December 2017; pp. 1-7. [CrossRef] 
9. Fang, J.; Zhao, S.; Shang, L.; Zhou, X.; Zhang, C. Application of Project-Based Learning in Analog Electronic Technology Course. In Proceedings of the International Conference on Education Innovation and Social Science (ICEISS 2017), Jinan, China, 29-30 November 2017; Atlantis Press: Jinan, China, 2017; pp. 130-133.

10. Mantri, A.; Dutt, S.; Gupta, J.; Chitkara, M. Design and Evaluation of a PBL-Based Course in Analog Electronics. IEEE Trans. Educ. 2008, 51, 432-438. [CrossRef]

11. Nerguizian, V.; Rafaf, M. Problems and projects based approach for analog electronic circuits' course. In Proceedings of the 12th World MultiConference on Systemics, Cybernetics and Informatics (WMSCI 2008), Orlando, FL, USA, 29 June-2 July 2008 ; pp. 152-156.

12. Kataria, D.; Sanchez, G. Design on Project-Based Learning for Analog Circuits. In Proceedings of the 2020 IEEE Frontiers in Education Conference (FIE), Uppsala, Sweden, 21-24 October 2020; pp. 1-4.

13. Schultz, S.; Hutchings, B.L. Designing a Sustainable Large-scale Project-based Learning (PBL) Experience for Juniors in Electrical and Computer Engineering. In Proceedings of the ASEE Annual Conference \& Exposition, Salt Lake City, UT, USA, 23 June-27 July 2021. [CrossRef]

14. LeBoeuf, R.; Gómez, J.T. Autonomous audio heater car: A comprehensive project-based analog design experience. Int. J. Electr. Eng. Educ. 2018, 55, 155-167. [CrossRef]

15. Seth, D.; Tangorra, J.; Ibrahim, A. Measuring undergraduate students' self-efficacy in engineering design in a project-based design course. In Proceedings of the 2015 IEEE Frontiers in Education Conference (FIE), El Paso, TX, USA, 21-24 October 2015; pp. 1-8. [CrossRef]

16. Chen, J.; Kolmos, A.; Du, X. Forms of implementation and challenges of PBL in engineering education: A review of literature. Eur. J. Eng. Educ. 2020, 46, 90-115. [CrossRef]

17. Horowitz, P.; Hill, W. The Arts of Electronics, 3rd ed.Cambridge University Press: New York, NY, USA, 2015.

18. Marsi, N.; Majlis, B.Y.; Hamzah, A.A.; Mohd-Yasin, F. High reliability of MEMS packaged capacitive pressure sensor employing 3C-SiC for high temperature. Energy Procedia 2015, 68, 471-479. [CrossRef]

19. Yasin, F.; Tye, K.; Reaz, M. Design and implementation of interface circuitry for cmos-based saw gas sensors. In Proceedings of the 2005 IEEE International SOC Conference, Herndon, VA, USA, 25-28 September 2005. [CrossRef]

20. Mohd-Yasin, F.; Khaw, M.K.; Reaz, M.B.I. Techniques of RFID Systems: Architecture and Applications. Microw. J. 2006, 49, 62-74.

21. Available online: https://www.altium.com/altium-designer (accessed on 16 August 2021).

22. Simons, K.D.; Klein, J.D. The Impact of Scaffolding and Student Achievement Levels in a Problem-based Learning Environment. Instr. Sci. 2006, 35, 41-72. [CrossRef]

23. Goh, K. What Good Teachers Do to Promote Effective Student Learning in a Problem-Based Learning Environment. Aust. J. Educ. Dev. Psychol. 2014, 14, 159-166.

24. Carless, D.; Chan, K.K.H.; To, J.; Lo, M.; Barrett, E. Developing students' capacities for evaluative judgement through analysing exemplars. In Developing Evaluative Judgement in Higher Education; Routledge: London, UK, 2018; pp. 108-116. [CrossRef]

25. Waters, R.; McCracken, M. Assessment and evaluation in problem-based learning. In Proceedings of the Frontiers in Education 1997 27th Annual Conference. Teaching and Learning in an Era of Change, Pittsburgh, PA, USA, 5-8 November 1997; Volume 2, pp. 689-693.

26. Pierrakos, O.; Anderson, R.; Barrella, E. A developmental and adaptive Problem Based Learning (PBL) model across the curriculum: From theory to practice in integrating and assessing PBL experiences across the James Madison University engineering curriculum. In Proceedings of the 2016 IEEE Frontiers in Education Conference (FIE), Erie, PA, USA, 12-15 October 2016; pp. 1-2. [CrossRef]

27. Shute, V.J. Focus on formative feedback. Rev. Educ. Res. 2008, 78, 153-189. [CrossRef]

28. Webb, M.E.; Prasse, D.; Phillips, M.; Kadijevich, D.M.; Angeli, C.; Strijker, A.; Carvalho, A.A.; Andresen, B.B.; Dobozy, E.; Laugesen, H. Challenges for IT-Enabled Formative Assessment of Complex 21st Century Skills. Technol. Knowl. Learn. 2018, 23, 441-456. [CrossRef]

29. Yang, X. An Approach of Project-Based Learning: Bridging the Gap between Academia and Industry Needs in Teaching Integrated Circuit Design Course. IEEE Trans. Educ. 2021, in press. [CrossRef] 